\title{
Prion Protein in Glioblastoma Multiforme
}

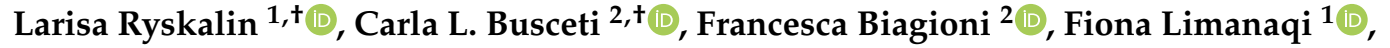 \\ Pietro Familiari ${ }^{3}$, Alessandro Frati ${ }^{2}$ and Francesco Fornai ${ }^{1,2, * \mathbb{D}}$ \\ 1 Department of Translational Research and New Technologies in Medicine and Surgery, University of Pisa, \\ via Roma 55, 56126 Pisa, Italy; larisa.ryskalin@unipi.it (L.R.); f.limanaqi@studenti.unipi.it (F.L.) \\ 2 I.R.C.C.S. Neuromed, via Atinense 18, 86077 Pozzilli, Italy; carla.busceti@neuromed.it (C.L.B.); \\ francesca.biagioni@neuromed.it (F.B.); alessandro.frati@uniroma1.it (A.F.) \\ 3 Department of Neuroscience, Mental Health and Sense Organs NESMOS, Sapienza University of Rome, \\ 00185 Rome, Italy; pietro.familiari@uniroma1.it \\ * Correspondence: francesco.fornai@neuromed.it or francesco.fornai@med.unipi.it \\ $\dagger$ These authors contributed equally to this work.
}

Received: 12 September 2019; Accepted: 14 October 2019; Published: 15 October 2019

\begin{abstract}
The cellular prion protein $(\mathrm{PrPc})$ is an evolutionarily conserved cell surface protein encoded by the PRNP gene. PrPc is ubiquitously expressed within nearly all mammalian cells, though most abundantly within the CNS. Besides being implicated in the pathogenesis and transmission of prion diseases, recent studies have demonstrated that PrPc contributes to tumorigenesis by regulating tumor growth, differentiation, and resistance to conventional therapies. In particular, PrPc over-expression has been related to the acquisition of a malignant phenotype of cancer stem cells (CSCs) in a variety of solid tumors, encompassing pancreatic ductal adenocarcinoma (PDAC), osteosarcoma, breast cancer, gastric cancer, and primary brain tumors, mostly glioblastoma multiforme (GBM). Thus, PrPc is emerging as a key in maintaining glioblastoma cancer stem cells' (GSCs) phenotype, thereby strongly affecting GBM infiltration and relapse. In fact, PrPc contributes to GSCs niche's maintenance by modulating GSCs' stem cell-like properties while restraining them from differentiation. This is the first review that discusses the role of PrPc in GBM. The manuscript focuses on how PrPc may act on GSCs to modify their expression and translational profile while making the micro-environment surrounding the GSCs niche more favorable to GBM growth and infiltration.
\end{abstract}

Keywords: cellular prion protein; glioma stem cells; autophagy; exosomes; cell-to-cell communication; stemness; differentiation

\section{Introduction}

The cellular prion protein (PrPc) is a highly conserved cell surface glycoprotein encoded by the PRNP gene, which is located on the short arm of chromosome 20 [1]. In humans, PrPc is expressed in various peripheral tissues, and to a higher extent in the nervous system [2]. Although the physiological role of PrPc remains to be fully established, its misfolded isoform scrapie $\operatorname{PrP}(\operatorname{PrPSc})$ is known to be key in the pathogenesis and transmission of prion diseases [3,4]. Prion diseases can be sporadic, inherited or infectious, and they include Creutzfeldt-Jakob disease (CJD), Gerstmann-Sträussler-Sheinker syndrome (GSS), fatal familial insomnia (FFI), kuru, bovine spongiform encephalopathy (BSE), and chronic wasting disease (CWD) [5].

PrPc misfolding occurs due to modifications in its secondary structure consisting of a decreased length of coiling $\alpha$-helixes that are replaced by a long strip of $\beta$-sheets. The latter contributes to forming insoluble and protease-resistant PrPSc [6]. Within prion-infected brains, PrPSc forms pathological protein aggregates, which act as seeds for normal PrPc [7]. The accumulation of misfolded PrP may also derive from slowed PrPc clearance, which may be due, at least in part, to alterations in cell 
clearing pathways, mostly autophagy (ATG) (Figure 1). As proof of concept, ATG inducers foster PrPsc removal [8,9]. This is not surprising, as a wide class of "prion-like", prone-to-misfold proteins (such as alpha-synuclein, SOD1, TDP-43, and FUS) may accumulate when a failure in cell clearing systems occurs [10,11].

Besides supporting the role of PrPsc as an infectious agent of prion disease, PRNP knockout (KO) experimental models have provided some insights into the physiological function of $\operatorname{PrPc}[12,13]$. In the nervous system, PrPc is involved in neurite extension, neuronal differentiation, and neuroprotection [14,15]. More in general, PrPc is involved in copper metabolism, signal transduction, cell proliferation, adhesion, and migration [16]. Thus, albeit promoting differentiation of resident stem cells, PrPc may also promote stemness and cell proliferation, depending on specific conditions [17-19].

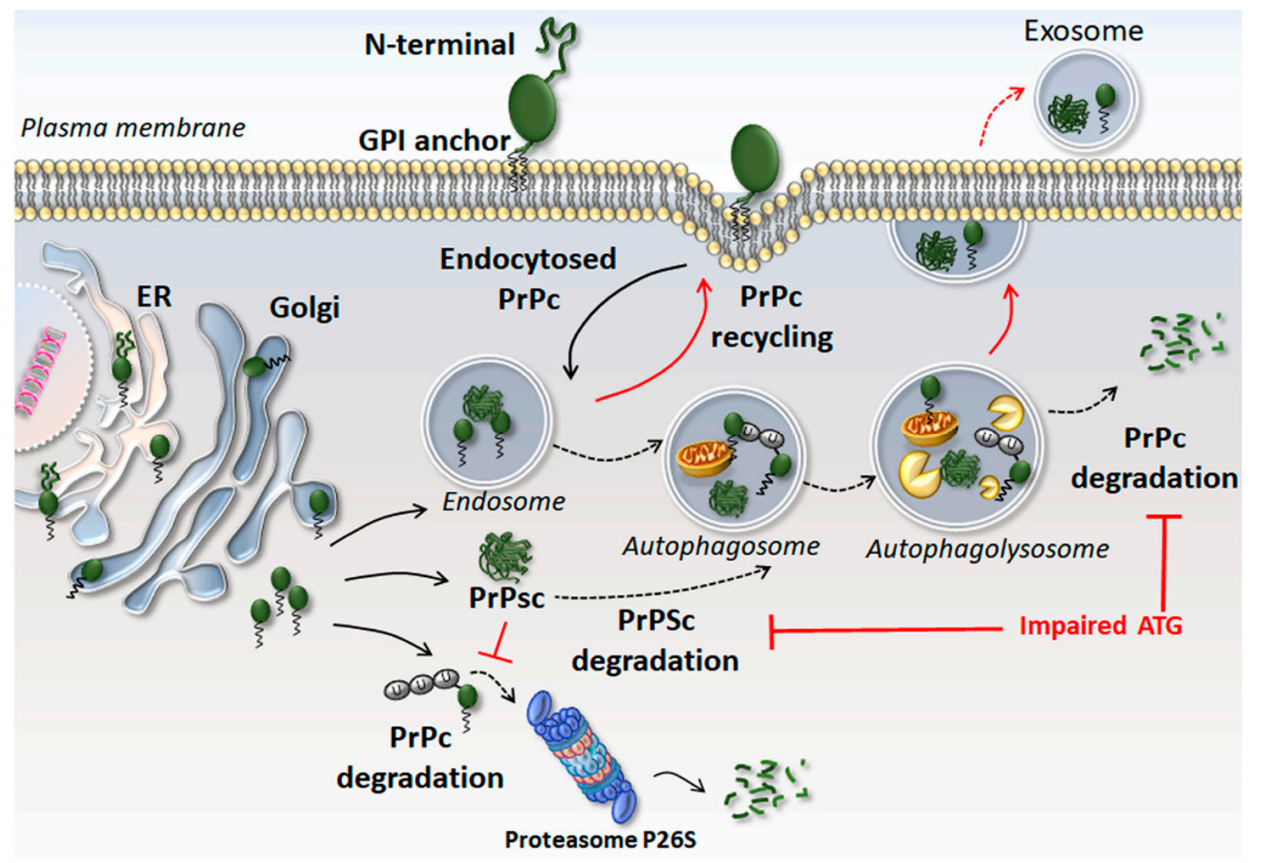

Figure 1. Structure and turnover of the cellular prion protein $(\mathrm{PrPc})$. The synthesis of PrPc requires the entry of the nascent protein into the lumen of the endoplasmic reticulum (ER), where the N-terminal signal peptide is removed, while a glycosyl-phosphatidyl-inositol (GPI) anchor remains attached to the C-terminal domain. Then, the protein moves to the Golgi apparatus to undergo post-translational modifications. Once completely folded, PrPc moves along the secretory pathway towards the outer leaflet of the plasma membrane, where it anchors via the GPI lipid moiety. Here, GPI-anchored PrPc is strategically associated with lipid rafts, suggesting an involvement in signal transduction and cell-to-cell communication. The clearance of PrPc depends on autophagy (ATG) and P26S proteasome systems. The accumulation of misfolded PrP leads to the formation of insoluble scrapie PrP (PrPSc), which may also derive from slowed PrPc clearance due to a failure of ATG. When ATG is impaired, endocytosed PrPc and PrPSc are rapidly recycled back to the plasma membrane or released extracellularly through exosomes. Black solid arrows indicate molecular steps (PrPc endocytosis, PrPc conversion into PrPSc, PrPs ubiquitination and recognition by the proteasome); black dotted arrows indicate ATG progression (fusion of PrPc-containing endosomes with autophagosomes and formation of autophagolysosomes), and PrPc/PrPSc degradation; red solid lines indicate the effects of ATG impairment; red dotted arrows indicate the exosomal release of undigested PrPc/PrPSc in the extracellular space.

The discovery of PrPc expression in different types of stem cells joined with evidence on PrPc overexpression in a variety of tumors has recently prompted its investigation in cancer stem cell (CSC) research [20-23]. CSCs are endowed with enhanced self-renewal, sustained proliferation, and tumor-initiating potential. Thus, they are pivotal in fueling tumor growth and conferring therapeutic 
resistance, while sustaining tumor infiltration and relapse. This applies to both hematopoietic and solid tumors, where PrPc is markedly overexpressed, including pancreatic ductal adenocarcinoma (PDAC), breast cancer, gastric and colorectal cancer, and gliomas [21-32]. High levels of PrPc are associated with an enhanced CSCs' tumorigenic potential, proliferation, and invasion, along with greater metastatic capacity, drug resistance, and angiogenesis. On the other hand, $\operatorname{PrPc}$ downregulation/inhibition suppresses tumor stemness, growth, proliferation, invasiveness, and angiogenesis [21,22,24-32].

Among CNS tumors, glioblastoma multiforme (GBM) is the most prevalent and malignant glioma in adults. To date, most of the therapeutic approaches for GBM consist of targeting tumor-specific aberrant signaling pathways. Despite promising results in pre-clinical trials, molecularly based therapies have shown limited efficacy in GBM patients. Thus, GBM remains one of the most challenging brain tumors. GBM infiltration and therapeutic resistance are mainly due to a subpopulation of highly proliferative CSCs, which are specifically identified as glioblastoma cancer stem cells (GSCs), harboring increased growth rate, self-renewal, pluripotency, and clonogenic potential [22,23]. As GSCs are considered as the main contributor to GBM initiation, growth, tissue invasion, and relapse, targeting GSCs represents one of the most promising avenues for developing effective strategies for GBM treatment. This topic was specifically dealt with in a manuscript we authored in the present special issue [33]. Instead, the aim of the present review was to discuss recent data on the role of PrPc as a main driver of CSCs, with a special focus on GSCs and GBM biology. The findings herein discussed may provide novel insights on the role of PrPc as a potential therapeutic target to restore GSCs' differentiation potential, thereby suppressing GSCs tumorigenicity.

\section{The Physiological Function of the Cellular Prion Protein (PrPc)}

Albeit occurring in various human peripheral tissues and cell types, $\mathrm{PrPc}$ is highly expressed within the nervous system, where it is implicated in brain development as well as neuronal and glial homeostasis and function [12,14,15,34-36]. PrPc is involved in synaptic transmission and plasticity, neurite outgrowth, neuronal excitability, and myelin maintenance [16]. Intriguingly, pioneer studies have indicated that $P R N P-K O$ mice could develop normally without any apparent alterations in CNS structure and behavior [37]. This might be due to the compensatory role of two proteins belonging to the PrP family, namely Doppel and Shadoo [38,39]. Nonetheless, recent studies demonstrated that mice lacking PrPc or expressing a mutant PrPc isoform resulted in severe motor alterations due to impaired excitability and synaptic plasticity within cerebellar granule neurons $[40,41]$.

$\operatorname{PrPc}$ is clustered on the plasma membrane within lipid rafts, where it interacts with a variety of receptors and molecules to transduce intracellular signals [42]. For instance, PrPc binding with the heat-shock-related protein STI-1 (stress-inducible protein 1; also known as HOP, Hsp70/Hsp90 organizing protein) increases protein synthesis, triggers neuroprotective signals, and promotes axonal growth through the phosphoinositide 3-kinases/Akt/mammalian target of rapamycin (PI3K/Akt/mTOR), cyclic adenosine monophosphate/protein kinase A (cAMP/PKA), and the mitogen-activated protein kinase/extracellular-signal-regulated kinase (MAPK/ERK) signaling pathways [15,43-45]. Even intracellular endocytosed PrPc can promote neuronal survival via binding to the adaptor protein Grb2 and subsequent activation of the MAPK/ERK pathway [46]. Again, the interaction between PrPc and several extracellular matrix components, encompassing both proteins and cell-surface receptors, can elicit ERK-mediated neurotrophic effects [47,48]. Finally, the neural cell adhesion molecule (NCAM) associates with PrPc to promote neurite outgrowth through the activation of the cytosolic kinase Fyn $[14,49]$.

PrPc is also implicated in stemness modulation and, mostly, in self-renewal and proliferation of tissue-resident stem cells. In baseline conditions, PrP controls pluripotency gene transcription and proliferation of hematopoietic, mammary gland, mesenchymal, embryonic, and neural stem cells $[17,18,50-54]$. In the CNS, PrPc regulates neurogenesis by promoting self-renewal, proliferation, and neuronal differentiation of normal neural stem cells (NSCs) (Figure 2) [19,53-55]. In detail, increased expression of PrPc correlates with NSC proliferation and differentiation within the subependymal 
ventricular zone (SVZ), one of the most active germinal regions of the CNS, which continuously generates newborn differentiated neurons [56]. This occurs through PrPc-NCAM interactions [54] or via PrPc-dependent potentiation of Notch signaling [19]. Silencing of PrPc in cultured human embryonic stem cells suppresses their differentiation towards a neural progenitor [55]. In line with this, neural tubes from PRNP-KO early murine embryos possess markedly reduced expression of the neural stem cell markers Sox2 and Nestin [19].

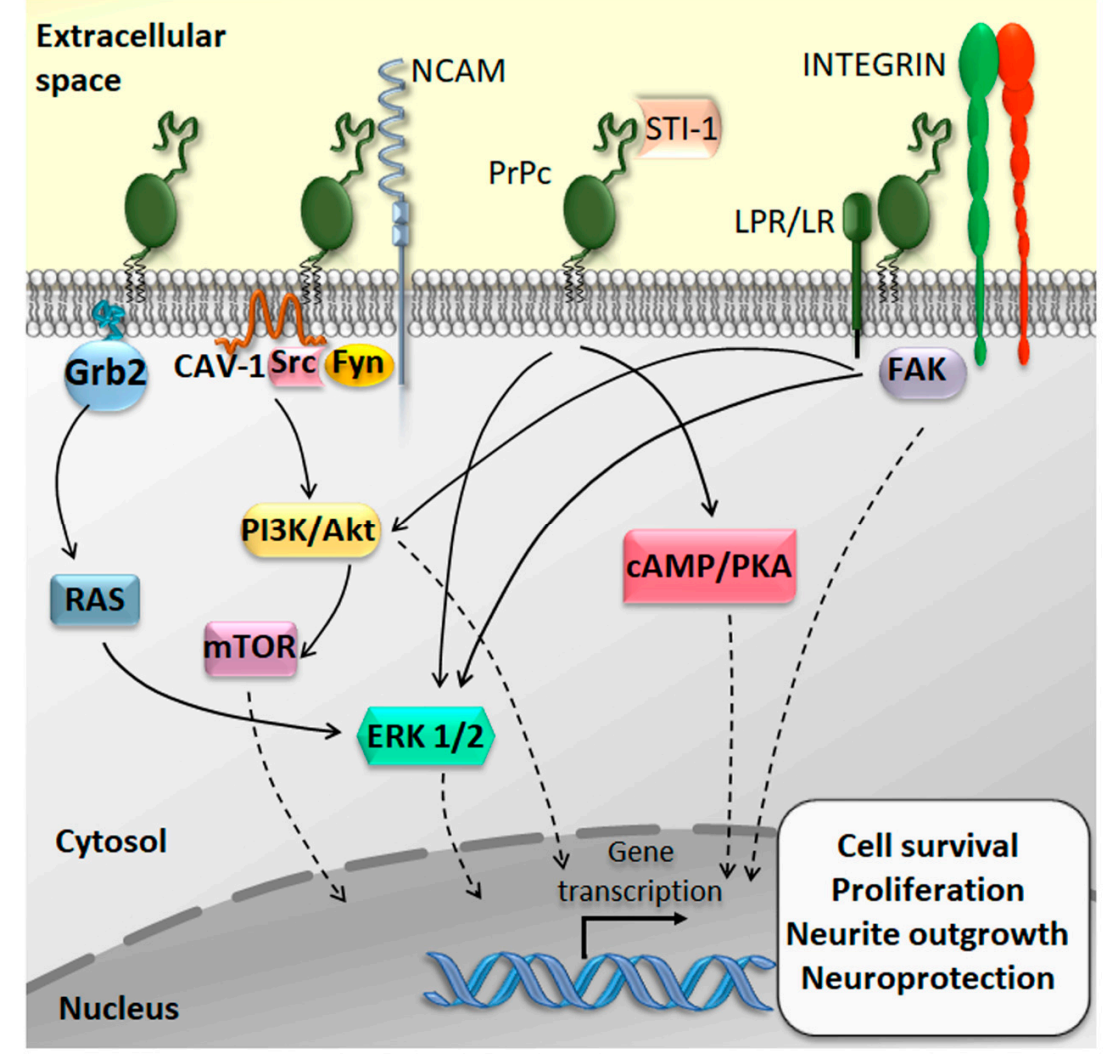

Figure 2. The physiological function of the cellular prion protein $(\mathrm{PrPc})$ within the CNS. The interaction of PrPc with several receptors and proteins located in close proximity to PrPc leads to the activation of downstream signaling pathways, consisting mainly of phosphoinositide 3-kinases/Akt/mammalian target of rapamycin (PI3K/Akt/mTOR) and RAS/MAPK/ERK, which induce neurotrophic effects within CNS stem cell niches. PrPc regulates neurogenesis by controlling self-renewal, proliferation, and differentiation of normal neural stem cells (NSCs). At the cellular level, PrPc is involved in cell proliferation, adhesion and differentiation, and intracellular communication. Black solid arrows indicate the PrPc-related molecular steps leading to the activation of intracellular signalling pathways; black dotted arrows indicate the nuclear shuttling and subsequent transcription of genes related to cell survival, proliferation and neuroprotection.

PrPc may promote NSCs' survival and stemness by acting as an antioxidant chaperone. In detail, upon stressful conditions (i.e., serum deprivation), an increase in intracellular reactive oxygen species (ROS) levels promotes $\beta$-mediated proteolytic cleavage of PrPc into a C-terminal and N-terminal fragment $[57,58]$. The latter is released extracellularly to trigger the MEK1 pathway, which sustains the antioxidant effects of PrPc [59].

Recent findings suggest that PrPc is implicated in cell-to-cell communication within neuronal networks. In fact, the removal of the glycosyl-phosphatidyl-inositol (GPI)-anchor generates soluble PrPc, which is released extracellularly to act both as an autocrine and paracrine neurotrophic factor. In line with this, PrPc and its ligand STI-1 are released from neurons and astrocytes through exosomes [60-62], small extracellular vesicles originating from the endosomal system as multivesicular bodies (MVBs) 
merging with the plasma membrane. In addition, PrPc can stimulate per se exosome secretion via caveolin-1 (CAV1)-dependent ATG suppression. In fact, PrPc stimulates CAV1 cell internalization, which inhibits ATG5-ATG12 engagement. This impedes MVBs fusion with autophagosomes while increasing their secretion as exosomes [63]. Conversely, ATG induction via mTORC1 suppression inhibits exosomal prion release [62]. Thus, PrPc appears to be a key in cell-to-cell communication facilitating astrocyte-astrocyte/neuron homophilic and/or heterophilic interactions.

These aspects are seminal in CSCs biology in general, and GBM in particular, where PrPc is markedly overexpressed (Section 3). In fact, the SVZ represents a "hot zone" for GBM initiation, as GSCs reside within the perivascular niche of the SVZ and the dentate gyrus of the hippocampus where they give rise to a tumorigenic bulk within the healthy brain parenchyma.

In this scenario, increased levels of PrPc within the SVZ may overstimulate the niche, leading to abnormal NSCs' self-renewal and proliferation up to the generation, expansion, and maintenance of an aberrant tumorigenic niche containing GSCs. This may occur through aberrantly activated pathways such as hyperactive Notch1, and PI3K/Akt/mTOR, which are known to sustain both PrPc activity and GSCs' stemness and proliferation. As recently reviewed, in GBM, the hyperactivation of Notch1 and mTOR is also linked to an impairment of ATG [33]. Thus, ATG failure represents one of the possible mechanisms leading to altered PrPc clearance and abnormal exosomal release in GBM. In the next section, we discuss evidence on the tumor-promoting role of PrPc in GBM specifically.

\section{PrPc in Glioblastoma and Glioma Cancer Stem Cells}

PrPc overexpression occurs in a variety of tumours, including breast [20], colorectal [21,27,28,30-32], gastric [25], lung [64], and pancreatic [26,29] cancer. As recently reported, PrPc is overexpressed in brain tumors as well, including meningioma, schwannoma [65], astrocytoma, and GBM [22-24,66]. According to a consensus view, increased levels of PrPc endow CSCs with self-renewal, proliferative [65-67], migratory, and invasive capacities [21,23,68], along with increased resistance to anti-cancer agents [30,31,69].

The role of PrPc is becoming more and more important in GBM, making such a primary brain tumor reminiscent of a prion disorder. An overexpression of $\mathrm{PrPc}$ and Doppel at both protein and mRNA levels occurs in human GBM tumor samples, which correlates with tumor malignancy and poor prognosis [24]. Similarly, increased expression of PrPc/STI-1(HOP) in human GBM samples is associated with tumor malignancy and lower patient survival [66].

PrPc is highly expressed within human GBM cell lines [70,71]. Intriguingly, PrPc production in GBM cells peaks during the G1 phase of the cell cycle, suggesting a key role of PrP in sustaining CSC growth through enhanced protein synthesis [70]. This is in line with what has been reported in gastric cancer cells, where PrPc upregulation promotes tumorigenesis and CSCs' proliferation through PI3K/Akt pathway activation and G1/S phase transition [25].

PrPc overexpression sustains the oncogenic properties of malignant gliomas by promoting GSCs' self-renewal, proliferation, and pluripotency [22-24,66,71-73]. This occurs, for instance, through PrPc-STI-1/HOP binding, which induces GSCs' proliferation through the activation of MAPK/ERK1/2 and PI3K/Akt pathways [22,23,71].

$\operatorname{PrPc}$ is pivotal in maintaining GSCs' stem-like phenotype while restraining them from differentiation. In fact, when GBM cells are cultured as neurospheres, they display upregulated levels of PrPc/HOP along with the stemness markers CD133, CD15, Oct4, and Sox2. Exogenous HOP administration increases GSC proliferation and self-renewal in a PrPc-dependent manner [23]. Again, increased levels of PrPc are correlated with an enhanced in vivo tumorigenicity, as well as in vitro GSCs' proliferation rate and expression of the stemness and self-renewal markers Nanog and Sox2 [24]. Similarly, in colorectal cancer cells, PrPc overexpression is accompanied by the upregulation of the stemness markers Oct4, Nanog, Sox2, and ALDH1A1, which is correlated with tumor growth, proliferation, and angiogenesis [31].

Besides GBM, PrPc overexpression occurs in meningioma and schwannoma human samples bearing loss-of-function mutations in the neurofibromatosis type 2 (NF2) gene [65]. In schwannoma 
cells, PrPc contributes to increased proliferation, cell-matrix adhesion, and survival by activating the 37/67 kDa non-integrin laminin receptor (LR37/67) and downstream ERK1/2 and PI3K/Akt signaling pathways. Remarkably, PrPc protein is abundantly released from schwannoma cells either via exosomes or as a free peptide, suggesting that it may act in an autocrine and/or paracrine manner to promote CSCs' tumorigenicity [65].

The equilibrium between PrPc synthesis and clearance, which determines the intracellular amount of PrPc, depends in part on the ATG pathway. In fact, ATG stimulation increases PrP degradation while ATG occlusion fosters PrP accumulation or exosomal secretion [8,9,62,74]. This latter represents a key point in GBM biology. In fact, suppression of ATG occurs in GBM, which is key for maintaining the stem-like properties of GSCs, thus supporting tumor growth, relapse, infiltration, and radio/chemo-resistance [33]. On the other hand, ATG induction by rapamycin suppresses xenograft GBM growth and proliferation in GBM cell lines and primary cell cultures via shifting their cycle from S to G1 phase [75]. This, in turn, is correlated with a suppression of the stemness marker Nestin, and induction of GSCs' differentiation towards a neuron-like phenotype as shown by the upregulation of the mitotic neuronal markers $\beta$ IIII-tubulin, NeuroD, and NeuN [76]. This is not surprising, as promoting differentiation towards a neuronal phenotype is distinctive of mTOR-inhibiting and/or ATG-inducing compounds even in normal CNS tissue [77-81]. These data are in line with growing literature indicating that many tumors, including GBM, benefit from an ATG enhancement [76,81-84].

It is remarkable that effects of PrPc in glioma cells' proliferation and self-renewal rely on the very same mTOR activation and ATG suppression [85]. Thus, a failure of ATG may impede intracellular PrPc degradation while fostering its exosomal release. These metabolic conditions, which are shared by GBM cells, are prominent within the sub-population forming the GSCs [33], which explains why GSCs are characterized by an abundant release of exosomes enriched in tumor-promoting mRNAs, miRNAs, along with PrP [86]. Upon their release within the extracellular milieu, these tumor-derived messages are delivered to neighbor recipient cells to modify their translational profile, thus making the microenvironment nearby the GSC niche more favorable for GBM growth and infiltration $[87,88]$.

These observations cast the hypothesis that PrPc affects all crucial steps allowing GSCs niche maintenance while sustaining GSCs' stem-like features and tumorigenicity. Thus, interfering with PrPc expression and metabolism, for instance through ATG modulation, may provide a novel strategy for inducing an epigenetic shift within CSCs towards a neuronal phenotype. In the next section, we provide an overview of the experimental studies centered on PrPc inhibition/downregulation as a strategy to combat CSCs/GSCs, including those related to ATG activation.

\section{Targeting PrPc in Cancer Stem Cells}

Although targeting of PrPc has not yet been tested therapeutically in cancer, several experimental studies point to PrP downregulation/inhibition as a potential anti-cancer strategy in a variety of tumors. For instance, in colon cancer cells, treatment with anti-PrP antibodies reduces cell proliferation and invasiveness, even though an increased efficacy is observed in combination with the chemotherapeutic drugs irinotecan, 5-fluorouracil, cisplatin, and doxorubicin [27]. Similarly, combining PRNP silencing with fucoidan provides an enhanced efficacy against colorectal CSCs' proliferation and migration in vitro, while reducing tumor volume and angiogenesis in vivo [28].

Either RNAi-mediated downregulation of PrPc or administration of anti-PrPc monoclonal antibodies inhibits both in vitro and in vivo tumorigenicity and invasiveness of colorectal CSCs by abrogating epithelial to mesenchymal transition (EMT) related to the ERK2 (MAPK1) pathway [21]. Similarly, $P R N P$ silencing abrogates colorectal cancer cell stem-like and mesenchymal-like phenotype through inhibiting the recruitment of the Hippo pathway effectors YAP and TAZ, and the TGF $\beta$ pathway [32]. Knockdown of PrPc expression decreases lung adenocarcinoma cells' lamellipodium formation, in vitro migration, and invasion, as well as in vivo experimental lung metastasis, which is associated with reduced JNK phosphorylation and reduced protein levels of a transcriptional activator of the PRNP promoter, namely, the nuclear factor interleukin 3 (NFIL3) [64]. 
In human PDAC and melanoma cell lines, $\operatorname{PrP}$ occurs as a pro-PrP isoform, being neither glycosylated nor GPI-anchored, albeit retaining the GPI anchor peptide signal sequence (GPI-PSS) [26,89]. This latter interacts with filamin A (FLNA) and integrin $\beta 1$ to disrupt the cytoskeletal organization and promote cancer cell invasiveness and migration. Inhibiting PrP expression by shRNA or via GPI-PSS-targeting peptides reduces PDAC and melanoma cell proliferation and invasiveness in vitro as well as tumor growth in vivo [26,89]. In addition to filamin A, PrPc interacts with Notch1, forming a PrPc/FLNA/Notch1 complex, which is associated with enhanced PDAC proliferation, invasiveness, and xenograft tumor growth [29]. These effects are reverted by PrPc silencing through Notch1 downregulation, and combining PrPc and Notch1 inhibition is more effective than targeting single pathways alone.

Targeting the GPI anchor of PrPc was investigated as a device for targeting cancer cell proliferation and metastasis in renal carcinoma through tissue inhibitor of metalloproteinase (TIMP) engineering [90]. Fusing the TIMP-1 protein to the GPI anchor of PrP creates a membrane-tethered complex, which co-localizes on the cell surface with membrane type 1-matrix metalloproteinase (MT1-MMP). This prevents MMP-mediated proteolysis of ECM components while reducing cancer cell growth and proliferation in vitro as well as in mouse xenografts [90].

Downregulating PrPc abrogates CSCs' resistance to chemotherapy. Secreted PrPc can directly sequester chemotherapeutic drugs, blocking their cytotoxic activity, as shown in breast cancer cells. Genetic depletion of PrPc prevents such an interaction while sensitizing breast CSCs to chemotherapy [91]. Down-regulation of PrPc by siRNA sensitizes breast cancer cells to adriamycin and tumor necrosis factor-related apoptosis-inducing ligand (TRAIL) [20]. Moreover, administration of chlorpromazine, which exerts anti-prion effects, inhibits CSCs' proliferation while preventing resistance to ionizing radiation and chemotherapeutic drugs in melanoma, breast cancer, and glioma [92-94].

Many of the beneficial effects of PrPc inhibition, including sensitization to chemotherapy, rely on the downregulation of the PI3K/Akt pathway, which, in turn, is bound to ATG stimulation. For instance, PrPc silencing counteracts the increased colorectal CSCs' survival, proliferation, and 5-fluorouracil (5-FU) resistance through downregulation of PI3K/Akt [30]. In gastric cancer cells, in vitro administration of the Akt inhibitor LY294002 or Akt siRNAs leads to inhibition of PrPc-induced and CyclinD1-related CSC proliferation, G1/S phase transition, and multidrug drug resistance [25]. PrPc-induced multi-drug-resistance in gastric cancer cells is also attenuated by inhibition of PI3K/Akt following the knockdown of the PrPc-interacting protein LRP37 [95].

Although these studies did not directly address the role of ATG, evidence was provided in GBM indicating that PrPc silencing by DNA-antisense oligonucleotides promotes mTOR-dependent ATG activation to halt GSCs' proliferation and growth [85]. These consist of the induction of LC3-II, Beclin-1, and a simultaneous decrease in p62, Bcl-2, along with inhibition of mTOR. Even PrPc degradation by the proteasome system was shown to decrease tumor progression, which is remarkable because the very same Akt/mTOR pathway synergistically modulates both p26S proteasome and ATG [96,97]. In detail, the tumorigenicity of colorectal cancer cells is associated with PrPc accumulation and upregulation of heat-shock $70 \mathrm{kDa}$ protein-1-like (HSPA1L), which, in turn, stabilizes the hypoxia-inducible factor-1 $\alpha$ $(\mathrm{HIF}-1 \alpha)$ protein. This latter interacts with the ubiquitin-protein E3 ligase glycoprotein 78 (GP78) to inhibit proteasome-dependent degradation of PrPc. Thus, targeting the HSPA1L/HIF-1 $\alpha /$ GP78 axis may counteract PrPc accumulation and tumor progression by stimulating cell-clearing systems [98].

Noteworthy, similar to what reported for PI3K/Akt/mTOR inhibition and ATG activation [76], PrPc downregulation counteracts GBM growth and self-renewal by promoting CSCs' differentiation. For instance, the blockade of PrPc-HOP/STI-1 interaction by means of a HOP peptide mimicking the PrPc-binding site ( $\left.\mathrm{HOP}_{230-245}\right)$ counteracts GSCs' proliferation and self-renewal through inhibition of PI3K/Akt [66]. Similarly, administration of $\mathrm{HOP}_{230-245}$ peptide to mice bearing GBM xenografts decreases tumor volume while extending animals' survival [66]. In turn, PrPc/HOP silencing reduces GSCs' proliferation by downregulating the stemness markers CD133, CD15, Oct4, and Sox2, while promoting GSCs' differentiation [22]. These effects are replicated in vivo where the tumorigenic 
potential of GSCs is markedly inhibited in GBM xenografts lacking PrPc and/or HOP. PrPc depletion also impairs GSCs' migration and invasiveness by downregulating cell adhesion-related proteins [22].

Again, the downregulation of Notch1, which occurs as a downstream effect of PrPc silencing [29], inhibits the PI3K/Akt/mTOR pathway to abolish GSCs' stemness, self-renewal, invasiveness and in vivo tumor growth [99]. It is remarkable that these effects are reproduced by the ATG inducers AZD8055 and rapamycin, which suppress GSCs' self-renewal and abolish GSCs tumorigenicity through degradation and inhibition of Notch1 [84].

Indirect evidence for ATG involvement is provided in colorectal CSCs as well, where the combination of 5-fluorouracil (5-FU) with the ATG inducer melatonin inhibits PrPc, along with the expression of the stem cell markers Oct4, Nanog, Sox2, and ALDH1A1 while suppressing tumor growth, proliferation, and angiogenesis [31].

In summary, strategies aimed at downregulating PrPc expression, including stimulation of ATG-dependent PrPc clearance may produce beneficial effects in cancer in general, and in GBM in particular, by inhibiting CSCs' stemness, self-renewal, proliferation, invasiveness, and resistance to radio-/chemo-therapy (Figure 3).

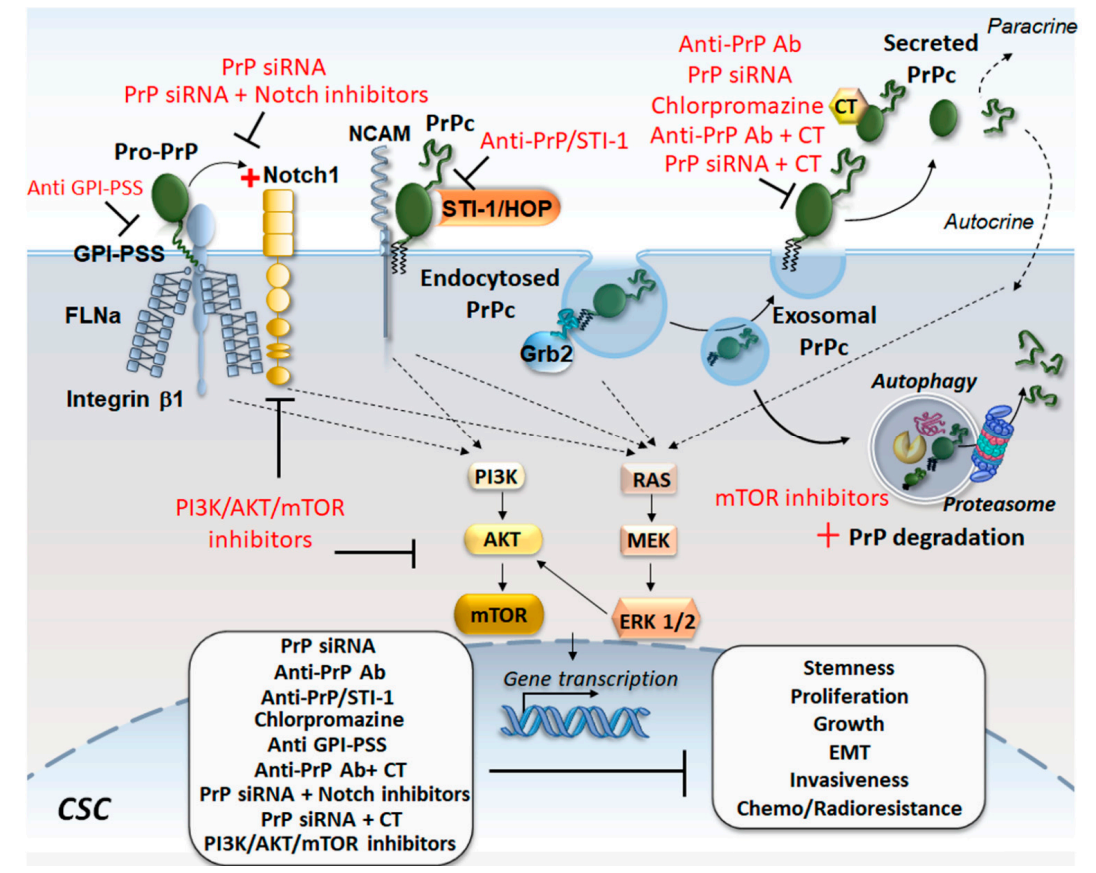

Figure 3. Targeting the cellular prion protein ( $\mathrm{PrPc})$ in cancer stem cells (CSCs). Strategies aimed at downregulating/inhibiting PrPc in CSCs include anti-PrP antibodies, PrP silencing (siRNA), administration of chlorpromazine, anti-PrP/stress-inducible protein 1 (STI-1)/Hsp70/Hsp90 organizing protein (HOP) peptides, PI3K/Akt/mTOR inhibitors, and combined strategies such as anti-PrP antibodies or PrP silencing (siRNA) with chemotherapy (CT), and PrP silencing with Notch inhibitors. These strategies counteract CSCs' stemness, self-renewal, growth, proliferation, epithelial to mesenchymal transition (EMT), invasiveness, and resistance to radio/chemotherapy. PI3K/Akt/mTOR inhibitors also counteract PrPc accumulation by fostering its degradation through the cell-clearing pathways' autophagy (ATG) and proteasome (red cross PrP degradation). ATG activation also downregulates Notch signaling, which is enhanced upon association with PrPc (red cross Notch1). In this way, PrP-induced pathways sustaining CSCs' phenotype and PrP exosome release are toned down. This is key, as secreted $\operatorname{PrP}$ acts via autocrine and paracrine mechanisms to foster CSCs' phenotype and can limit therapeutic drugs' efficacy via direct sequestration of CT. Black solid lines indicate molecular steps (arrows: Stimulation; " $\mathrm{T}$ "-shaped lines: Inhibition); black dotted arrows indicate PrPc-related molecular steps leading to the activation of intracellular signalling pathways. 


\section{Concluding Remarks}

Being strategically localized within lipid rafts, PrPc interacts with a number of binding partners to activate intracellular signaling pathways that modulate cell proliferation, adhesion, and differentiation. Although in physiological conditions PrPc expression is seminal for stem cell homeostasis, neurogenesis, and neuronal differentiation, PrPc overexpression may alter pivotal functions of stem cell biology up to sustaining the tumorigenic phenotype of CSCs. This occurs in a variety of tumors including GBM, wherein PrPc is emerging as both a prognostic biomarker and active player of cancer biology by promoting CSCs' self-renewal, stemness, proliferation, and invasiveness and resistance to radio/chemotherapy. In line with the evidence obtained in breast, colorectal, PDAC, and lung cancer among others, targeting PrPc may provide a therapeutic strategy for GBM by counteracting cancer progression, infiltration, and therapeutic resistance. Remarkably, abolishing PrPc may be beneficial in GBM by occluding GSCs' self-renewal capacity while restoring their ability to differentiate. Thus, PrPc maintains cancer stemness during tumor progression while its downregulation may induce the acquisition of a more differentiated and less oncogenic phenotype. Among the various strategies used to target $\mathrm{PrPc}$ in cancer, enhancing PrPc degradation by cell clearing systems may be key in GBM neurobiology. In fact, PrPc overexpression may be due to an unbalance between protein synthesis and clearance related to ATG failure, which occurs in GBM, especially within GSCs. Thus, ATG dysfunctions, along with PrPc accumulation and exosomal release are likely to be interconnected events sustaining GSCs phenotype. Targeting ATG dysfunctions to counteract PrPc accumulation deserves to be further investigated as a potential strategy to combat GSCs. Another issue that remains to be investigated is whether PrP in GBM exists as PrPsc besides PrPc.

Author Contributions: Original draft preparation, writing, review and art work, L.R. and C.L.B.; review, editing, and art work, F.B. and F.L. and P.F.; conceptualization, A.F. and F.L.; supervision, intellectual content, and paper coordination, F.F.

Funding: This work was funded by Ministero della Salute (Ricerca Corrente 2019).

Conflicts of Interest: The authors declare no conflict of interest.

\section{Abbreviations}

$\begin{array}{ll}\text { ATG } & \text { Autophagy } \\ \text { BSE } & \text { Bovine spongiform encephalopathy } \\ \text { cAMP } & \text { Cyclic adenosine monophosphate } \\ \text { CAV-1 } & \text { Caveolin-1 } \\ \text { CJD } & \text { Creutzfeldt-Jakob disease } \\ \text { CNS } & \text { Central nervous system } \\ \text { CSCs } & \text { Cancer stem cells } \\ \text { CWD } & \text { Chronic wasting disease } \\ \text { EMT } & \text { Epithelial-mesenchymal transition } \\ \text { ERK } & \text { Extracellular-signal-regulated kinase } \\ \text { FFI } & \text { Fatal familial insomnia } \\ \text { FLNA } & \text { Filamin A } \\ \text { GP78 } & \text { Ubiquitin-protein E3 ligase glycoprotein 78 } \\ \text { GSCs } & \text { Glioma stem-like cells } \\ \text { GSS } & \text { Gerstmann-Sträussler-Sheinker syndrome } \\ \text { HIF-1 } \alpha & \text { Hypoxia-inducible factor-1 } \alpha \\ \text { HOP } & \text { Hsp70/Hsp90 organizing protein } \\ \text { HSPA1L } & \text { Heat-shock 70 kDa protein-1-like } \\ \text { LR/37/67 } & \text { 37/67kDa non-integrin laminin receptor } \\ \text { MAPK } & \text { Mitogen-activated protein kinase } \\ \text { MT1-MMP } & \text { Membrane type 1-matrix metalloproteinase } \\ \text { MVBs } & \text { Multivesicular bodies } \\ & \end{array}$




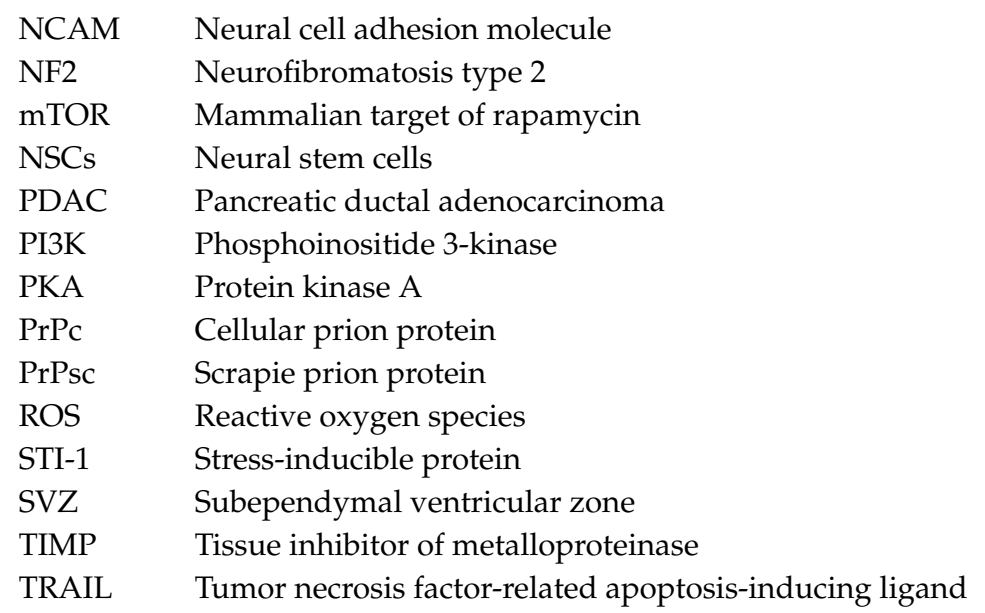

\section{References}

1. Oesch, B.; Westaway, D.; Wälchli, M.; McKinley, M.P.; Kent, S.B.; Aebersold, R.; Barry, R.A.; Tempst, P.; Teplow, D.B.; Hood, L.E.; et al. A cellular gene encodes scrapie PrP 27-30 protein. Cell 1985, 40, 735-746. [CrossRef]

2. Prusiner, S.B.; Scott, M.R.; DeArmond, S.J.; Cohen, F.E. Prion protein biology. Cell 1998, 93, 337-348. [CrossRef]

3. Stahl, N.; Borchelt, D.R.; Hsiao, K.; Prusiner, S.B. Scrapie prion protein contains a phosphatidylinositol glycolipid. Cell 1987, 51, 229-240. [CrossRef]

4. Prusiner, S.B. Prions. Proc. Natl. Acad. Sci. 1998, 95, 13363-13383. [CrossRef]

5. Fornai, F.; Ferrucci, M.; Gesi, M.; Bandettini di Poggio, A.; Giorgi, F.S.; Biagioni, F.; Paparelli, A. A hypothesis on prion disorders: Are infectious, inherited, and sporadic causes so distinct? Brain Res. Bull. 2006, 69, 95-100. [CrossRef] [PubMed]

6. Pan, K.M.; Baldwin, M.; Nguyen, J.; Gasset, M.; Serban, A.; Groth, D.; Mehlhorn, I.; Huang, Z.; Fletterick, R.J.; Cohen, F.E. Conversion of alpha-helices into beta-sheets features in the formation of the scrapie prion proteins. Proc. Natl. Acad. Sci. USA 1993, 90, 10962-10966. [CrossRef] [PubMed]

7. Ma, J.; Lindquist, S. Conversion of PrP to a self perpetuating PrPSc-like conformation in the cytosol. Science 2002, 298, 1785-1788. [CrossRef] [PubMed]

8. Heiseke, A.; Aguib, Y.; Riemer, C.; Baier, M.; Schätzl, H.M. Lithium induces clearance of protease resistant prion protein in prion-infected cells by induction of autophagy. J. Neurochem. 2009, 109, 25-34. [CrossRef] [PubMed]

9. Jeong, J.K.; Moon, M.H.; Lee, Y.J.; Seol, J.W.; Park, S.Y. Autophagy induced by the class III histone deacetylase Sirt1 prevents prion peptide neurotoxicity. Neurobiol. Aging 2013, 34, 146-156. [CrossRef]

10. Natale, G.; Pompili, E.; Biagioni, F.; Paparelli, S.; Lenzi, P.; Fornai, F. Histochemical approaches to assess cell-to-cell transmission of misfolded proteins in neurodegenerative diseases. Eur. J. Histochem. 2013, 57 , e5. [CrossRef]

11. Ryskalin, L.; Busceti, C.L.; Limanaqi, F.; Biagioni, F.; Gambardella, S.; Fornai, F. A Focus on the Beneficial Effects of Alpha Synuclein and a Re-Appraisal of Synucleinopathies. Curr. Protein Pept. Sci. 2018, 19, 598-611. [CrossRef] [PubMed]

12. Mitteregger, G.; Vosko, M.; Krebs, B.; Xiang, W.; Kohlmannsperger, V.; Nölting, S.; Hamann, G.F.; Kretzschmar, H.A. The role of the octarepeat region in neuroprotective function of the cellular prion protein. Brain Pathol. 2007, 17, 174-183. [CrossRef] [PubMed]

13. Biasini, E.; Turnbaugh, J.A.; Unterberger, U.; Harris, D.A. Prion protein at the crossroads of physiology and disease. Trends Neurosci. 2012, 35, 92-103. [CrossRef] [PubMed]

14. Santuccione, A.; Sytnyk, V.; Leshchyns'ka, I.; Schachner, M. Prion protein recruits its neuronal receptor NCAM to lipid rafts to activate p59fyn and to enhance neurite outgrowth. J. Cell Biol. 2005, 169, 341-354. [CrossRef] [PubMed] 
15. Roffé, M.; Beraldo, F.H.; Bester, R.; Nunziante, M.; Bach, C.; Mancini, G.; Gilch, S.; Vorberg, I.; Castilho, B.A.; Martins, V.R.; et al. Prion protein interaction with stress-inducible protein 1 enhances neuronal protein synthesis via mTOR. Proc. Natl. Acad. Sci. USA 2010, 107, 13147-13152. [CrossRef]

16. Wulf, M.A.; Senatore, A.; Aguzzi, A. The biological function of the cellular prion protein: An update. BMC Biol. 2017, 15, 34. [CrossRef]

17. Zhang, C.C.; Steele, A.D.; Lindquist, S.; Lodish, H.F. Prion protein is expressed on long-term repopulating hematopoietic stem cells and is important for their self-renewal. Proc. Natl. Acad. Sci. USA 2006, 103, 2184-2189. [CrossRef]

18. Santos, T.G.; Silva, I.R.; Costa-Silva, B.; Lepique, A.P.; Martins, V.R.; Lopes, M.H. Enhanced neural progenitor/stem cells self-renewal via the interaction of stress-inducible protein 1 with the prion protein. Stem Cells 2011, 29, 1126-1136. [CrossRef]

19. Martin-Lannerée, S.; Halliez, S.; Hirsch, T.Z.; Hernandez-Rapp, J.; Passet, B.; Tomkiewicz, C.; Villa-Diaz, A.; Torres, J.M.; Launay, J.M.; Béringue, V.; et al. The Cellular Prion Protein Controls Notch Signaling in Neural Stem/Progenitor Cells. Stem Cells 2017, 35, 754-765. [CrossRef]

20. Meslin, F.; Hamai, A.; Gao, P.; Jalil, A.; Cahuzac, N.; Chouaib, S.; Mehrpour, M. Silencing of prion protein sensitizes breast adriamycin-resistant carcinoma cells to TRAIL-mediated cell death. Cancer Res. 2007, 67, 10910-10919. [CrossRef]

21. Du, L.; Rao, G.; Wang, H.; Li, B.; Tian, W.; Cui, J.; He, L.; Laffin, B.; Tian, X.; Hao, C.; et al. CD44-positive cancer stem cells expressing cellular prion protein contribute to metastatic capacity in colorectal cancer. Cancer Res. 2013, 73, 2682-2694. [CrossRef] [PubMed]

22. Corsaro, A.; Bajetto, A.; Thellung, S.; Begani, G.; Villa, V.; Nizzari, M.; Pattarozzi, A.; Solari, A.; Gatti, M.; Pagano, A.; et al. Cellular prion protein controls stem cell-like properties of human glioblastoma tumor-initiating cells. Oncotarget 2016, 7, 38638-38657. [CrossRef] [PubMed]

23. Iglesia, R.P.; Prado, M.B.; Cruz, L.; Martins, V.R.; Santos, T.G.; Lopes, M.H. Engagement of cellular prion protein with the co-chaperone Hsp70/90 organizing protein regulates the proliferation of glioblastoma stem-like cells. Stem Cell Res. Ther. 2017, 8, 76. [CrossRef] [PubMed]

24. Comincini, S.; Ferrara, V.; Arias, A.; Malovini, A.; Azzalin, A.; Ferretti, L.; Benericetti, E.; Cardarelli, M.; Gerosa, M.; Passarin, M.G.; et al. Diagnostic value of PRND gene expression profiles in astrocytomas: Relationship to tumor grades of malignancy. Oncol. Rep. 2007, 17, 989-996. [CrossRef] [PubMed]

25. Liang, J.; Pan, Y.; Zhang, D.; Guo, C.; Shi, Y.; Wang, J.; Chen, Y.; Wang, X.; Liu, J.; Guo, X.; et al. Cellular prion protein promotes proliferation and G1/S transition of human gastric cancer cells SGC7901 and AGS. FASEB J. 2007, 21, 2247-2256. [CrossRef]

26. Li, C.; Yu, S.; Nakamura, F.; Yin, S.; Xu, J.; Petrolla, A.A.; Singh, N.; Tartakoff, A.; Abbott, D.W.; Xin, W.; et al. Binding of pro-prion to filamin A disrupts cytoskeleton and correlates with poor prognosis in pancreatic cancer. J. Clin. Investig. 2009, 119, 2725-2736. [CrossRef]

27. McEwan, J.F.; Windsor, M.L.; Cullis-Hill, S.D. Antibodies to prion protein inhibit human colon cancer cell growth. Tumour Biol. 2009, 30, 141-147. [CrossRef]

28. Yun, C.W.; Yun, S.; Lee, J.H.; Han, Y.S.; Yoon, Y.M.; An, D.; Lee, S.H. Silencing Prion Protein in HT29 Human Colorectal Cancer Cells Enhances Anticancer Response to Fucoidan. Anticancer Res. 2016, 36, 4449-4458. [CrossRef]

29. Wang, Y.; Yu, S.; Huang, D.; Cui, M.; Hu, H.; Zhang, L.; Wang, W.; Parameswaran, N.; Jackson, M.; Osborne, B.; et al. Cellular Prion Protein Mediates Pancreatic Cancer Cell Survival and Invasion through Association with and Enhanced Signaling of Notch1. Am. J. Pathol. 2016, 186, 2945-2956. [CrossRef]

30. Lee, J.H.; Yun, C.W.; Lee, S.H. Cellular prion protein enhances drug resistance of colorectal cancer cells via regulation of a survival signal pathway. Biomol. Ther. 2018, 26, 313-321. [CrossRef]

31. Lee, J.H.; Yun, C.W.; Han, Y.S.; Kim, S.; Jeong, D.; Kwon, H.Y.; Kim, H.; Baek, M.J.; Lee, S.H. Melatonin and 5-fluorouracil co-suppress colon cancer stem cells by regulating cellular prion protein-Oct4 axis. J. Pineal Res. 2018, 65, e12519. [CrossRef] [PubMed]

32. Le Corre, D.; Ghazi, A.; Balogoun, R.; Pilati, C.; Aparicio, T.; Martin-Lannerée, S.; Marisa, L.; Djouadi, F.; Poindessous, V.; Crozet, C.; et al. The cellular prion protein controls the mesenchymal-like molecular subtype and predicts disease outcome in colorectal cancer. EBioMedicine 2019, 46, 94-104. [CrossRef] [PubMed] 
33. Ryskalin, L.; Gaglione, A.; Limanaqi, F.; Biagioni, F.; Familiari, P.; Frati, A.; Esposito, V.; Fornai, F. The Autophagy Status of Cancer Stem Cells in Gliobastoma Multiforme: From Cancer Promotion to Therapeutic Strategies. Int. J. Mol. Sci. 2019, 20, 3824. [CrossRef] [PubMed]

34. Lima, F.R.; Arantes, C.P.; Muras, A.G.; Nomizo, R.; Brentani, R.R.; Martins, V.R. Cellular prion protein expression in astrocytes modulates neuronal survival and differentiation. J. Neurochem. 2007, 103, 2164-2176. [CrossRef] [PubMed]

35. Arantes, C.; Nomizo, R.; Lopes, M.H.; Hajj, G.N.; Lima, F.R.; Martins, V.R. Prion protein and its ligand stress inducible protein 1 regulate astrocyte development. Glia 2009, 57, 1439-1449. [CrossRef]

36. Hartmann, C.A.; Martins, V.R.; Lima, F.R.S. High levels of cellular prion protein improve astrocyte development. FEBS Lett. 2013, 587, 238-244. [CrossRef]

37. Büeler, H.; Fischer, M.; Lang, Y.; Bluethmann, H.; Lipp, H.P.; DeArmond, S.J.; Prusiner, S.B.; Aguet, M.; Weissmann, C. Normal development and behaviour of mice lacking the neuronal cell-surface PrP protein. Nature 1992, 356, 577-582. [CrossRef]

38. Moore, R.C.; Lee, I.Y.; Silverman, G.L.; Harrison, P.M.; Strome, R.; Heinrich, C.; Karunaratne, A.; Pasternak, S.H.; Chishti, M.A.; Liang, Y.; et al. Ataxia in prion protein (PrP)-deficient mice is associated with upregulation of the novel PrP-like protein doppel. J. Mol. Biol. 1999, 292, 797-817. [CrossRef]

39. Watts, J.C.; Drisaldi, B.; Ng, V.; Yang, J.; Strome, B.; Horne, P.; Sy, M.S.; Yoong, L.; Young, R.; Mastrangelo, P.; et al. The CNS glycoprotein Shadoo has $\operatorname{Pr} P(\mathrm{C})$-like protective properties and displays reduced levels in prion infections. EMBO J. 2007, 26, 4038-4050. [CrossRef]

40. Prestori, F.; Rossi, P.; Bearzatto, B.; Lainé, J.; Necchi, D.; Diwakar, S.; Schiffmann, S.N.; Axelrad, H.; D’Angelo, E. Altered neuron excitability and synaptic plasticity in the cerebellar granular layer of juvenile prion protein knock-out mice with impaired motor control. J. Neurosci. 2008, 28, 7091-7103. [CrossRef]

41. Senatore, A.; Colleoni, S.; Verderio, C.; Restelli, E.; Morini, R.; Condliffe, S.B.; Bertani, I.; Mantovani, S.; Canovi, M.; Micotti, E.; et al. Mutant PrP suppresses glutamatergic neurotransmission in cerebellar granule neurons by impairing membrane delivery of VGCC $\alpha(2) \delta-1$ Subunit. Neuron 2012, 74, 300-313. [CrossRef] [PubMed]

42. Chen, S.; Mangé, A.; Dong, L.; Lehmann, S.; Schachner, M. Prion protein as trans-interacting partner for neurons is involved in neurite outgrowth and neuronal survival. Mol. Cell Neurosci. 2003, 22, 227-233. [CrossRef]

43. Chiarini, L.B.; Freitas, A.R.; Zanata, S.M.; Brentani, R.R.; Martins, V.R.; Linden, R. Cellular prion protein transduces neuroprotective signals. EMBO J. 2002, 21, 3317-3326. [CrossRef] [PubMed]

44. Zanata, S.M.; Lopes, M.H.; Mercadante, A.F.; Hajj, G.N.; Chiarini, L.B.; Nomizo, R.; Freitas, A.R.; Cabral, A.L.; Lee, K.S.; Juliano, M.A.; et al. Stress-inducible protein 1 is a cell surface ligand for cellular prion that triggers neuroprotection. EMBO J. 2002, 21, 3307-3316. [CrossRef] [PubMed]

45. Lopes, M.H.; Hajj, G.N.; Muras, A.G.; Mancini, G.L.; Castro, R.M.; Ribeiro, K.C.; Brentani, R.R.; Linden, R.; Martins, V.R. Interaction of cellular prion and stress-inducible protein 1 promotes neuritogenesis and neuroprotection by distinct signaling pathways. J. Neurosci. 2005, 25, 11330-11339. [CrossRef] [PubMed]

46. Spielhaupter, C.; Schätzl, H.M. PrPC directly interacts with proteins involved in signaling pathways. J. Biol. Chem. 2001, 276, 44604-44612. [CrossRef] [PubMed]

47. Graner, E.; Mercadante, A.F.; Zanata, S.M.; Forlenza, O.V.; Cabral, A.L.; Veiga, S.S.; Juliano, M.A.; Roesler, R.; Walz, R.; Minetti, A.; et al. Cellular prion protein binds laminin and mediates neuritogenesis. Brain Res. Mol. Brain Res. 2000, 76, 85-92. [CrossRef]

48. Beraldo, F.H.; Arantes, C.P.; Santos, T.G.; Machado, C.F.; Roffe, M.; Hajj, G.N.; Lee, K.S.; Magalhães, A.C.; Caetano, F.A.; Mancini, G.L.; et al. Metabotropic glutamate receptors transduce signals for neurite outgrowth after binding of the prion protein to laminin $\gamma 1$ chain. FASEB J. 2011, 25, 265-279. [CrossRef]

49. Schmitt-Ulms, G.; Legname, G.; Baldwin, M.A.; Ball, H.L.; Bradon, N.; Bosque, P.J.; Crossin, K.L.; Edelman, G.M.; DeArmond, S.J.; Cohen, F.E.; et al. Binding of neural cell adhesion molecules (N-CAMs) to the cellular prion protein. J. Mol. Biol. 2001, 314, 1209-1225. [CrossRef]

50. Mohanty, S.T.; Cairney, C.J.; Chantry, A.D.; Madan, S.; Fernandes, J.A.; Howe, S.J.; Moore, H.D.; Thompson, M.J.; Chen, B.; Thrasher, A.; et al. A small molecule modulator of prion protein increases human mesenchymal stem cell lifespan, ex vivo expansion, and engraftment to bone marrow in NOD/SCID mice. Stem Cells 2012, 30, 1134-1143. [CrossRef] 
51. Lee, Y.J.; Baskakov, I.V. Treatment with normal prion protein delays differentiation and helps to maintain high proliferation activity in human embryonic stem cells. J. Neurochem. 2010, 114, 362-373. [CrossRef] [PubMed]

52. Martellucci, S.; Santacroce, C.; Santilli, F.; Piccoli, L.; Delle Monache, S.; Angelucci, A.; Misasi, R.; Sorice, M.; Mattei, V. Cellular and Molecular Mechanisms Mediated by recPrP(C) Involved in the Neuronal Differentiation Process of Mesenchymal Stem Cells. Int. J. Mol. Sci. 2019, 20, 345. [CrossRef] [PubMed]

53. Steele, A.D.; Emsley, J.G.; Ozdinler, P.H.; Lindquist, S.; Macklis, J.D. Prion protein (PrPc) positively regulates neural precursor proliferation during developmental and adult mammalian neurogenesis. Proc. Natl. Acad. Sci. USA 2006, 103, 3416-3421. [CrossRef] [PubMed]

54. Prodromidou, K.; Papastefanaki, F.; Sklaviadis, T.; Matsas, R. Functional cross-talk between the cellular prion protein and the neural cell adhesion molecule is critical for neuronal differentiation of neural stem/precursor cells. Stem Cells 2014, 32, 1674-1687. [CrossRef] [PubMed]

55. Lee, Y.J.; Baskakov, I.V. The cellular form of the prion protein guides the differentiation of human embryonic stem cells into neuron-, oligodendrocyte-, and astrocyte-committed lineages. Prion 2014, 8, 266-275. [CrossRef]

56. Ryskalin, L.; Lazzeri, G.; Flaibani, M.; Biagioni, F.; Gambardella, S.; Frati, A.; Fornai, F. mTOR-Dependent Cell Proliferation in the Brain. Biomed. Res. Int. 2017, 2017, 7082696. [CrossRef]

57. Mange, A.; Beranger, F.; Poec'h, K.; Onodera, T.; Frobert, Y.; Lehmann, S. Alpha- and beta- cleavages of the amino-terminus of the cellular prion protein. Biol. Cell 2004, 96, 125-132. [CrossRef]

58. Watt, N.T.; Taylor, D.R.; Gillott, A.; Thomas, D.A.; Perera, W.S.S.; Hooper, N.M. Reactive oxygen species-mediated $\beta$-cleavage of the prion protein in the cellular response to oxidative stress. J. Biol. Chem. 2005, 280, 35914-35921. [CrossRef]

59. Haigh, C.L.; McGlade, A.R.; Collins, S.J. MEK1 transduces the prion protein N2 fragment antioxidant effects. Cell Mol. Life Sci. 2015, 72, 1613-1629. [CrossRef]

60. Février, B.; Laude, H.; Raposo, G.; Vilette, D. Exosomes: Carriers of prions? Med. Sci. 2005, 21, $132-133$.

61. Hajj, G.N.; Arantes, C.P.; Dias, M.V.; Roffé, M.; Costa-Silva, B.; Lopes, M.H.; Porto-Carreiro, I.; Rabachini, T.; Lima, F.R.; Beraldo, F.H.; et al. The unconventional secretion of stress-inducible protein 1 by a heterogeneous population of extracellular vesicles. Cell Mol. Life Sci. 2013, 70, 3211-3227. [CrossRef] [PubMed]

62. Abdulrahman, B.A.; Abdelaziz, D.H.; Schatzl, H.M. Autophagy regulates exosomal release of prions in neuronal cells. J. Biol. Chem. 2018, 293, 8956-8968. [CrossRef] [PubMed]

63. Dias, M.V.; Teixeira, B.L.; Rodrigues, B.R.; Sinigaglia-Coimbra, R.; Porto-Carreiro, I.; Roffé, M.; Hajj, G.N.; Martins, V.R. PRNP/prion protein regulates the secretion of exosomes modulating CAV1/caveolin-1-suppressed autophagy. Autophagy 2016, 12, 2113-2128. [CrossRef] [PubMed]

64. Lin, S.C.; Lin, C.H.; Shih, N.C.; Liu, H.L.; Wang, W.C.; Lin, K.Y.; Liu, Z.Y.; Tseng, Y.J.; Chang, H.K.; Lin, Y.C.; et al. Cellular prion protein transcriptionally regulated by NFIL3 enhances lung cancer cell lamellipodium formation and migration through JNK signaling. Oncogene 2019. [CrossRef] [PubMed]

65. Provenzano, L.; Ryan, Y.; Hilton, D.A.; Lyons-Rimmer, J.; Dave, F.; Maze, E.A. Cellular prion protein (PrPC) in the development of Merlin-deficient tumours. Oncogene 2017, 36, 6132-6142. [CrossRef] [PubMed]

66. Lopes, M.H.; Santos, T.G.; Rodrigues, B.R.; Queiroz-Hazarbassanov, N.; Cunha, I.W.; Wasilewska-Sampaio, A.P.; Costa-Silva, B.; Marchi, F.A.; Bleggi-Torres, L.F.; Sanematsu, P.I.; et al. Disruption of prion protein-HOP engagement impairs glioblastoma growth and cognitive decline and improves overall survival. Oncogene 2015, 34, 3305-3314. [CrossRef] [PubMed]

67. Cheng, Y.; Tao, L.; Xu, J.; Li, Q.; Yu, J.; Jin, Y.; Chen, Q.; Xu, Z.; Zou, Q.; Liu, X. CD44/cellular prion protein interact in multidrug resistant breast cancer cells and correlate with responses to neoadjuvant chemotherapy in breast cancer patients. Mol. Carcinog. 2014, 53, 686-697. [CrossRef]

68. de Lacerda, T.C.S.; Costa-Silva, B.; Giudice, F.S.; Dias, M.V.S.; de Oliveira, G.P.; Teixeira, B.L. Prion protein binding to HOP modulates the migration and invasion of colorectal cancer cells. Clin. Exp. Metastasis. 2016, 33, 441-451. [CrossRef]

69. Chieng, C.K.-L.; Say, Y.-H. Cellular prion protein contributes to LS 174T colon cancer cell carcinogenesis by increasing invasiveness and resistance against doxorubicin-induced apoptosis. Tumour Biol. J. Int. Soc. Oncodeve Biol. Med. 2015, 36, 8107-8120. [CrossRef] 
70. Kikuchi, Y.; Kakeya, T.; Yamazaki, T.; Takekida, K.; Nakamura, N.; Matsuda, H.; Takatori, K.; Tanimura, A.; Tanamoto, K.; Sawada, J. G1-dependent prion protein expression in human glioblastoma cell line T98G. Biol. Pharm. Bull. 2002, 25, 728-733. [CrossRef]

71. Erlich, R.B.; Kahn, S.A.; Lima, F.R.; Muras, A.G.; Martins, R.A.; Linden, R.; Chiarini, L.B.; Martins, V.R.; Moura Neto, V. STI1 promotes glioma proliferation through MAPK and PI3K pathways. Glia 2007, 55, 1690-1698. [CrossRef] [PubMed]

72. Azzalin, A.; Sbalchiero, E.; Barbieri, G.; Palumbo, S.; Muzzini, C.; Comincini, S. The doppel (Dpl) protein influences in vitro migration capability in astrocytoma-derived cells. Cell Oncol. 2008, 30, 491-501. [PubMed]

73. Fonseca, A.C.; Romão, L.; Amaral, R.F.; Assad Kahn, S.; Lobo, D.; Martins, S.; Marcondes de Souza, J.; Moura-Neto, V.; Lima, F.R. Microglial stress inducible protein 1 promotes proliferation and migration in human glioblastoma cells. Neuroscience 2012, 200, 130-141. [CrossRef]

74. Aguib, Y.; Heiseke, A.; Gilch, S.; Riemer, C.; Baier, M.; Schätzl, H.M.; Ertmer, A. Autophagy induction by trehalose counteracts cellular prion infection. Autophagy 2009, 5, 361-369. [CrossRef] [PubMed]

75. Arcella, F.; Biagioni, M.; Oliva, A.; Bucci, D.; Frati, A.; Esposito, V.; Cantore, G.; Giangaspero, F.; Fornai, F. Rapamycin inhibits the growth of glioblastoma. Brain Res. 2013, 1495, 37-51. [CrossRef] [PubMed]

76. Ferrucci, M.; Biagioni, F.; Lenzi, P.; Gambardella, S.; Ferese, R.; Calierno, M.T.; Falleni, A.; Grimaldi, A.; Frati, A.; Esposito, V.; et al. Rapamycin promotes differentiation increasing $\beta$ III-tubulin, NeuN, and NeuroD while suppressing nestin expression in glioblastoma cells. Oncotarget 2017, 8, 29574-29599. [CrossRef]

77. Cui, J.; He, W.; Yi, B.; Zhao, H.; Lu, K.; Ruan, H.; Ma, D. mTOR pathway is involved in ADP-evoked astrocyte activation and ATP release in the spinal dorsal horn in a rat neuropathic pain model. Neuroscience 2014, 275, 395-403. [CrossRef]

78. Goldshmit, Y.; Kanner, S.; Zacs, M.; Frisca, F.; Pinto, A.R.; Currie, P.D.; Pinkas-Kramarski, R. Rapamycin increases neuronal survival, reduces inflammation and astrocyte proliferation after spinal cord injury. Mol. Cell. Neurosci. 2015, 68, 82-91. [CrossRef]

79. Li, X.; Wu, C.; Chen, N.; Gu, H.; Yen, A.; Cao, L.; Wang, E.; Wang, L. PI3K/Akt/mTOR signaling pathway and targeted therapy for glioblastoma. Oncotarget 2016, 7, 33440-33450. [CrossRef]

80. Rodolfo, C.; Di Bartolomeo, S.; Cecconi, F. Autophagy in stem and progenitor cells. Cell. Mol. Life Sci. 2016, 73, 475-496. [CrossRef]

81. Ryskalin, L.; Limanaqi, F.; Biagioni, F.; Frati, A.; Esposito, V.; Calierno, M.T.; Lenzi, P.; Fornai, F. The emerging role of m-TOR up-regulation in brain Astrocytoma. Histol. Histopathol. 2017, 32, 413-431. [PubMed]

82. Zhuang, W.; Li, B.; Long, L.; Chen, L.; Huang, Q.; Liang, Z. Induction of autophagy promotes differentiation of glioma-initiating cells and their radiosensitivity. Int. J. Cancer 2011, 129, 2720-2731. [CrossRef] [PubMed]

83. Catalano, M.; D'Alessandro, G.; Lepore, F.; Corazzari, M.; Caldarola, S.; Valacca, C.; Faienza, F.; Esposito, V.; Limatola, C.; Cecconi, F.; et al. Autophagy induction impairs migration and invasion by reversing EMT in glioblastoma cells. Mol. Oncol. 2015, 9, 1612-1625. [CrossRef] [PubMed]

84. Tao, Z.; Li, T.; Ma, H.; Yang, Y.; Zhang, C.; Hai, L.; Liu, P.; Yuan, F.; Li, J.; Yi, L.; et al. Autophagy suppresses self-renewal ability and tumorigenicity of glioma-initiating cells and promotes Notch1 degradation. Cell Death Dis. 2018, 9, 1063. [CrossRef]

85. Barbieri, G.; Palumbo, S.; Gabrusiewicz, K.; Azzalin, A.; Marchesi, N.; Spedito, A.; Biggiogera, M.; Sbalchiero, E.; Mazzini, G.; Miracco, C.; et al. Silencing of cellular prion protein (PrPC) expression by DNA-antisense oligonucleotides induces autophagy-dependent cell death in glioma cells. Autophagy 2011, 7, 840-853. [CrossRef]

86. Skog, J.; Würdinger, T.; van Rijn, S.; Meijer, D.H.; Gainche, L.; Sena-Esteves, M.; Curry, W.T.; Carter, B.S.; Krichevsky, A.M.; Breakefield, X.O. Glioblastoma microvesicles transport RNA and proteins that promote tumour growth and provide diagnostic biomarkers. Nat. Cell Biol. 2008, 10, 1470-1476. [CrossRef]

87. Li, C.C.; Eaton, S.A.; Young, P.E.; Lee, M.; Shuttleworth, R.; Humphreys, D.T.; Grau, G.E.; Combes, V.; Bebawy, M.; Gong, J.; et al. Glioma microvesicles carry selectively packaged coding and non-coding RNAs which alter gene expression in recipient cells. RNA Biol. 2013, 10, 1333-1344. [CrossRef]

88. Liu, S.; Sun, J.; Lan, Q. Glioblastoma microvesicles promote endothelial cell proliferation through Akt/beta-catenin pathway. Int. J. Clin. Exp. Pathol. 2014, 7, 4857-4866.

89. Li, C.; Yu, S.; Nakamura, F.; Pentikäinen, O.T.; Singh, N.; Yin, S.; Xin, W.; Sy, M.S. Pro-prion binds filamin A, facilitating its interaction with integrin beta1, and contributes to melanomagenesis. J. Biol. Chem. 2010, 285, 30328-30339. [CrossRef] 
90. Jiang, B.; Liu, J.; Lee, M.H. Targeting a Designer TIMP-1 to the Cell Surface for Effective MT1-MMP Inhibition: A Potential Role for the Prion Protein in Renal Carcinoma Therapy. Molecules 2019, 24, 255. [CrossRef]

91. Wiegmans, A.P.; Saunus, J.M.; Ham, S.; Lobb, R.; Kutasovic, J.R.; Dalley, A.J.; Miranda, M.; Atkinson, C.; Foliaki, S.T.; Ferguson, K.; et al. Secreted cellular prion protein binds doxorubicin and correlates with anthracycline resistance in breast cancer. JCI Insight 2019, 4, e124092. [CrossRef] [PubMed]

92. Cooper, M.; Mishima, Y. Increased in vitro radio-sensitivity of malignant melanoma induced by the in vivo administration of chlorpromazine. British J. Dermatol. 1972, 86, 491-494. [CrossRef] [PubMed]

93. Yde, C.W.; Clausen, M.P.; Bennetzen, M.V.; Lykkesfeldt, A.E.; Mouritsen, O.G.; Guerra, B. The antipsychotic drug chlorpromazine enhances the cytotoxic effect of tamoxifen in tamoxifen-sensitive and tamoxifen-resistant human breast cancer cells. Anti-Cancer Drugs 2009, 20, 723-735. [CrossRef] [PubMed]

94. Oliva, C.R.; Zhang, W.; Langford, C.; Suto, M.J.; Griguer, C.E. Repositioning chlorpromazine for treating chemoresistant glioma through the inhibition of cytochrome c oxidase bearing the COX4-1 regulatory subunit. Oncotarget 2017, 8, 37568-37583. [CrossRef]

95. Luo, G.; Wang, W.; Wu, Q.; Lu, Y.; Su, T.; Gu, N.; Li, K.; Wang, J.; Du, R.; Zhao, X.; et al. MGr1-Antigen/37 $\mathrm{kDa}$ laminin receptor precursor promotes cellular prion protein induced multi-drug-resistance of gastric cancer. Oncotarget 2017, 8, 71630-71641. [CrossRef]

96. Zhao, J.; Zhai, B.; Gygi, S.P.; Goldberg, A.L. mTOR inhibition activates overall protein degradation by the ubiquitin proteasome system as well as by autophagy. Proc. Natl. Acad. Sci. USA 2015, 112, 15790-15797. [CrossRef]

97. Lazzeri, G.; Biagioni, F.; Fulceri, F.; Busceti, C.L.; Scavuzzo, M.C.; Ippolito, C.; Salvetti, A.; Lenzi, P.; Fornai, F. mTOR Modulates Methamphetamine-Induced Toxicity through Cell Clearing Systems. Oxid. Med. Cell. Longev. 2018, 2018, 6124745. [CrossRef]

98. Lee, J.H.; Han, Y.S.; Yoon, Y.M.; Yun, C.W.; Yun, S.P.; Kim, S.M.; Kwon, H.Y.; Jeong, D.; Baek, M.J.; Lee, H.J.; et al. Role of HSPA1L as a cellular prion protein stabilizer in tumor progression via HIF-1 $\alpha /$ GP78 axis. Oncogene 2017, 36, 6555-6567. [CrossRef]

99. Yi, L.; Zhou, X.; Li, T.; Liu, P.; Hai, L.; Tong, L.; Ma, H.; Tao, Z.; Xie, Y.; Zhang, C.; et al. Notch1 signaling pathway promotes invasion, self-renewal and growth of glioma initiating cells via modulating chemokine system CXCL12/CXCR4. J. Exp. Clin. Cancer Res. 2019, 38, 339. [CrossRef]

(C) 2019 by the authors. Licensee MDPI, Basel, Switzerland. This article is an open access article distributed under the terms and conditions of the Creative Commons Attribution (CC BY) license (http://creativecommons.org/licenses/by/4.0/). 